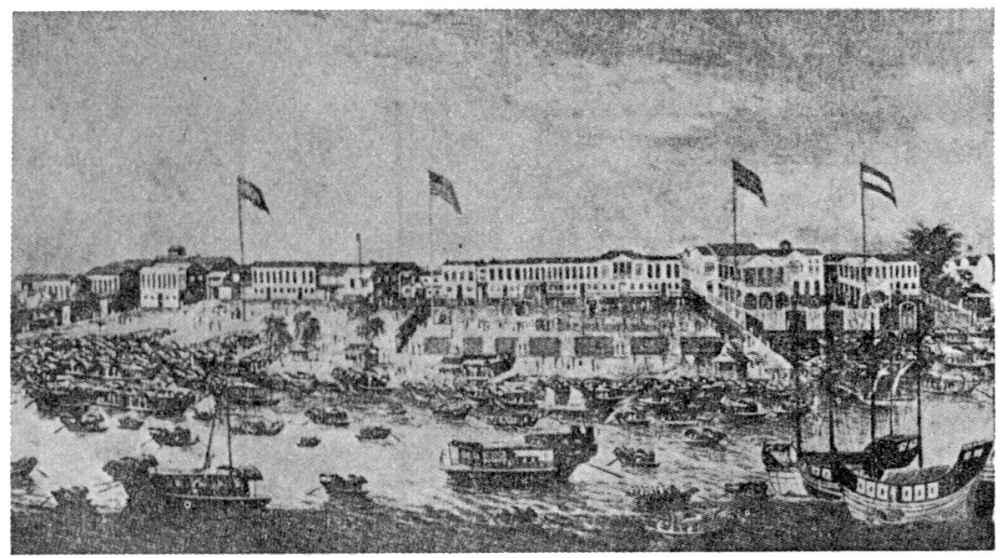

The Hongs of Old Canton

These buildings were the combined offices, storehouses, and residences of the foreign community at Canton in the early days of the China trade

due to the damp condition in which it was packed: The latest of these letters advises the Canton establishment to collect part of the value of the damaged silks from the various Chinese from whom they were bought.

"The matter needs thorough investigation," writes the correspondent from Hong Kong, "and we could advise that, in future shipments, the inspection be made by an experienced silk inspector, and not trusted to the honor of the Chinese dealers."

The forcible encroachment of the West on the carefully guarded seclusion of the ancient empire had substituted enmity and suspicion for the old friendly relations, precarious as they were, and without much real understanding on either side, and made it a virtue in the Chinese to thwart the intruder in every way. The battle was not yet won. The Chinese retreated step by step, still opposing a wall of passive resistance and elusive dealing to the onslaughts of the "barbarians."

\title{
Backstage with Edison
}

AN ITEM of timely interest has been discovered among a pile of old records given to the Baker Library by the United States Court of Appeals, in the facsimile of a notebook kept by Thomas A. Edison 


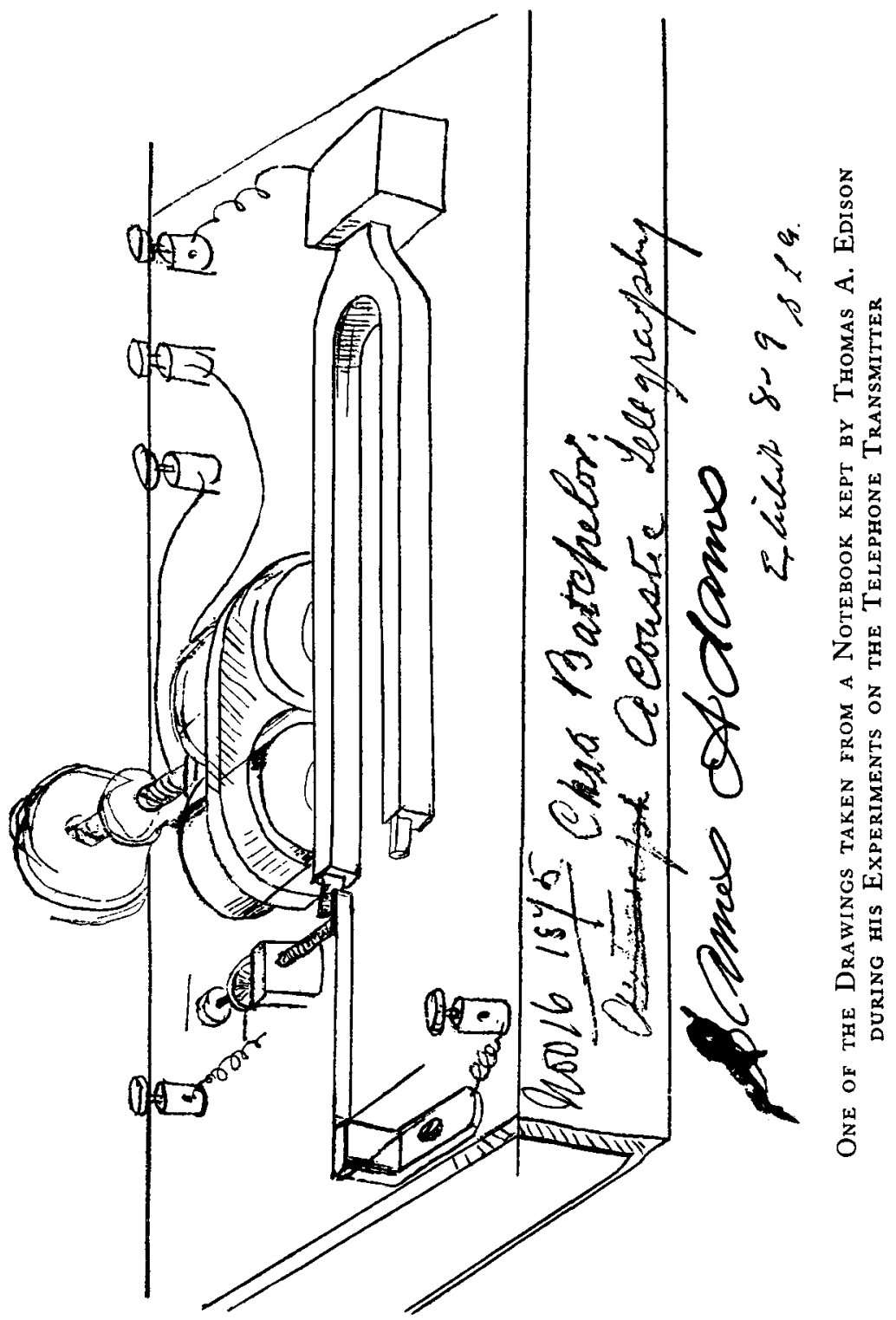


Bulletin of The Business Historical Society

2 I

EDISON'S EXHIBIT. 6-9.

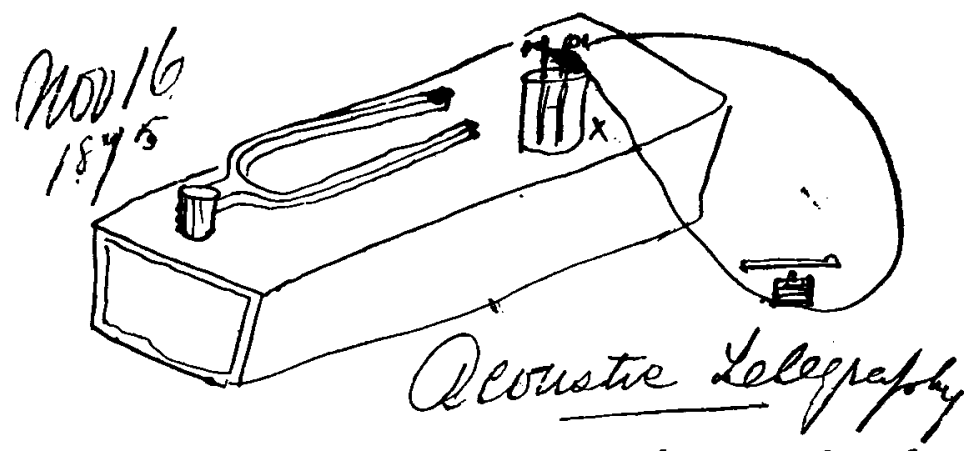

$x$ is a quackly polargeng 6 attern ret ah depalarger powarfuely weth the barat fin, wo the lañing for respond only to uctration in unewn wath to

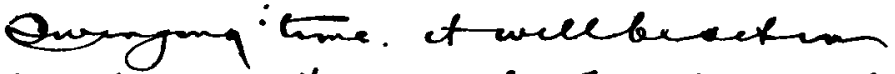
mothen क the en to Tumi cuser eitcke Repomant ax vebraling

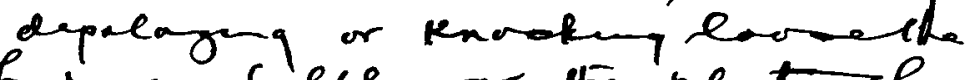
Gongum cibse. or the penter ob the 6 acly $X$ manan the stiength

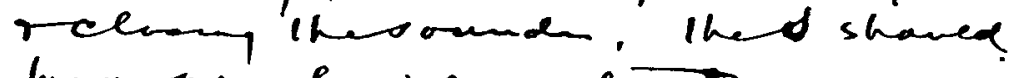

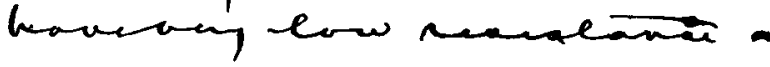

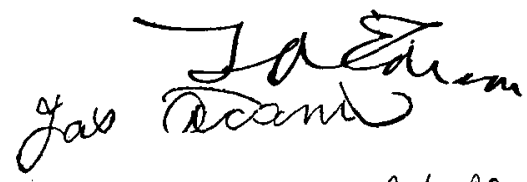

gotm gencese

Signed Drawing from Edison's Notebook

https://doi.org/10.1017/S000768050000773X Published online by Cambridge University Press 
during his experiments on the carbon telephone transmitter. It appears as part of the evidence in the telephone interference case of the American Bell Telephone Company vs. the National Telephone Manufacturing Company et al. The Court decided that the defendants were not infringing the Berliner patent, under which the Bell Telephone Company was operating, as their instruments embodied no invention of Berliner's, but only Edison's discovery of the carbon electrode and Hughes' discovery of what is described as "microphonic action, or the fact that sound waves produce remarkable variations of resistance at a loose or feeble contact between solid electrodes in constant contact, whereby speech may be transmitted."

The scrawled drawings, informal style, and enthusiastic comments of Mr. Edison's notes are refreshing and unexpected in their setting of court proceedings. Reading the hastily written pages one is transported from the court room, with its maze of technicalities and legal language, to Edison's laboratory, where one follows by daily steps the working out of the carbon transmitter which made the telephone a practical instrument.

The earliest drawings are dated November I6, 1875, several months before Bell's patent was issued. They are only very sketchily explained, at times only labelled "Acoustic telegraph." One has directions from Edison written across a corner, "Kreuse Please start on this right away with Jim. If you want brass there is an order you can fill on my desk."

In August, I876, after the date of Bell's patent, Edison makes a résumé of his experiments so far. He seems to have been much concerned with trying various materials for the diaphragm. He got his best results, he says, with a two-inch diaphragm, brass in the transmitter, and parchment in the receiver - "singing in any key can be transmitted accurately." With another arrangement they found that singing and playing on the cornet were transmitted perfectly.

As early as October, 1876 , he was experimenting with the plumbago film transmitter which he patented the following February. We find a rough drawing of a mouthpiece and disc, with the inscription, "this works but not so good as Plumbago on hard rubber." This was the material used for the disc patented, which is shown a few pages later. The second drawing is the original on which the application for the patent was made. At the time of this first patent, although he was working with carbon, he does not 
seem as yet to have conceived the idea of the electrical resistance of carbon varying inversely with the pressure upon it, on which his later patent was based.

In June, 1877, after the date of his second patent for an instrument which is pronounced by the Court "operative but not practical," we find, after some preliminary references to the same idea, an entry headed "experiments to determine the availability of Plumbago mixed with different substances for a disc which by variable pressure shall give us variable resistance." Shortly afterward follows a long series of experiments for determining the proper binder for the carbon. $15 \mathrm{grm}$ plumbago and $2 \mathrm{grm}$ isinglass is tried, which is "pretty good... Unknown plumbago mixture simply elegant. It now becomes necessary to find out what this combination is. We believe it is Plumbago with a large proportion of Isinglass or Gelatin."

With a combination of 15 grm plumbago and $2 \mathrm{grm}$ Woodbridge clay they got "whistling only by a fine adjustment, 'also whispering." I 5 grm plumbago and 2 grm starch gave "whispering best we have had yet seems like talking. We got the sh! all perfect on this." While 15 grm plumbago and 6 grm starch was extra good on "lowest faintest whisper." "Bully good!!!" is underlined three times at the bottom of the entry.

There are more notes on the telephone, and a few on the phonograph, and quite irrelevantly, on a page with an unlabelled drawing, "if that fellow don't go away I am going to put lights out and put Induction coil on him," signed "James Adams."

After this glimpse of the Edison laboratory during the progress of one of the great inventions of the present age, the evidence proceeds with caveats and patent specifications to the end of the volume. It is yet to be discovered how many more intimate bits of history are contained in this unpromising pile of law records.

\section{In Alemoriam}

THE Society has once more been unfortunate in losing a valued member, Mr. John Whittemore Farwell, of Boston. Born at Waltham, Massachusetts, in 1843, he was largely identified with the Massachusetts textile industry throughout his career. In I 872 he was a member of the Maine Legislature, and served in the Massachusetts Legislature in 1885 . But for the most part his interests were con- 